JSAP: Journal Syariah and Accounting Public

ISSN: 2622-3538

Available Online at https://journal.umgo.ac.id/index.php/JSAP/index

Vol. 3, No. 1 Juli 2020

DOI: $10.31314 /$ jsap.3.1.33-40.2020

\title{
KEBERADAAN GALERI INVESTASI BURSA EFEK INDONESIAUNIVERSITAS MUHAMMADIYAH GORONTALO TERHADAP MINAT MAHASISWA DALAM BERINVESTASI
}

\author{
Yustina Hiola ${ }^{1}$ Andika Paris ${ }^{2}$ \\ 1, Program Studi Akuntasi, Universitas Muhammadiyah Gorontalo, Indonesia \\ 2, Program Studi Ekonomi Pembangunan, Universit Muhammadiyaah Gorontalo, Indonesia \\ Email; yustinahiola@umgo.ac.id
}

Info Artikel: Diterima: 13 Februari 2020, Disetujui: 23 Februari 2020, Publish 15 Juli 2020

\begin{abstract}
:
Indonesia Stock Exchange (IDX) Investment Gallery at Universitas Muhammadiyah Gorontalo is the first investment gallery in the University at Gorontalo Province. Since it was formed at the end of 2017, this investment gallery has more than 100 stock investors. This research aimed to determine the existence of the stock exchange investment gallery at Universitas Muhammadiyah Gorontalo and its effect on the students' investment interest. The researcher used descriptive qualitative method. Data were collected by using a questionnaire that distributed to 40 students of Universitas Muhammadiyah Gorontalo as with two indicators, 1) understanding of galleries and 2) interest in investing. The results of the study showed that $45 \%$ or 18 respondents knew the existence of galleries, $42 \%$ or 17 respondents did not know the existence of galleries, and $13 \%$ or 5 respondents were doubtful. While the second indicator about investment interest, there were $46 \%$ or 19 respondents answered yes (interested), 33\% or 13 who answered not interested, and $21 \%$ or 8 respondents were doubtful.
\end{abstract}

Keywords: Gallery, Investment, Stock Exchange, Students, Interests

\begin{abstract}
Abstrak:
Galeri Investasi Bursa Efek Indonesia Universitas Muhammadiyah Gorontalo, adalah galeri pertama di kampus-kampus yang ada Gorontalo. Sejak terbentuk di akhir tahun 2017, galeri investasi ini telah berjalan kurang lebih hampir tiga tahun, dan telah memiliki lebih dari 100 investor saham. Tujuan penelitian ini, untuk mengetahui bagaimana keberadaan galeri investasi Universitas Muhammadiyah Gorontalo terhadap minat berinvestasi mahasiswa. Penelitian ini menggunakan pendekatan kualitatis deskriptif. Data diperoleh melalui kuesioner yang disebar pada 40 responden mahasiswa Universitas Muhammadiyah Gorontalo, dengan menggunakan dua indikator yang digunakan yaitu 1) pemahaman tentang galeri dan 2) minat berinvestasi. Hasil penelitian menyimpulkan bahwa, dari indikator pertama tentang keberadaan galeri, $45 \%$ atau 18 responden mengetahui keberadaan galeri, $42 \%$ atau 17 responden tidak tahu keberadaan galeri, dan $13 \%$ atau 5 responden menjawab ragu-ragu. Sedangkan indikator kedua tentang minat berinvestasi $46 \%$ atau 19 responden yang menjawab $\mathrm{Ya}$ (berminat), $33 \%$ atau 13 yang menjawab tidak berminat, dan $21 \%$ atau 8 responden menjawab ragu-ragu.
\end{abstract}

Kata kunci : Galeri, Investasi, Bursa Efek, Mahasiswa, Minat 


\section{PENDAHULUAN}

Pasar Modal memiliki peran penting bagi perekonomian suatu negara karena pasar modal menjalankan dua fungsi, yaitu pertama sebagai sarana bagi pendanaan usaha atau sebagai sarana bagi perusahaan untuk mendapatkan dana dari masyarakat pemodal (investor). Kedua, pasar modal menjadi sarana bagi masyarakat untuk berinvestasi pada instrument keuangan seperti saham, obligasi, reksa dana, dan lain-lain. Dengan demikian, masyarakat dapat menempatkan dana yang dimilikinya sesuai dengan karakteristik keuntungan dan risiko masing-masing instrument.

Bursa Efek Indonesia (BEI) selaku pengelola penjualan efek dilndonesia terus melakukan upaya-upaya untuk meningkatkan investasi masyarakat di pasar modal. Salah satunya dengan menambah jumlah Bank Administrator Rekening Dana Nasabah (RDN). Selain penambahan administrator RDN (Rekening Dana Nasabah), menurut Irmawati Amran selaku kepala devisi pengembangan investor Bursa Efek Indonesia (2016) pada saat ini BEI gencar melakukan pengenalan program "Yuk Nabung Saham". Program ini merupakan sebuah kampanye yang mengajak masyarakat Indonesia untuk berinvestasi di pasar modal melalui "share saving". Hanya dengan berbekal mulai Rp 100.000,- setiap bulannya, masyarakat dapat membeli saham melalui perusahaan sekuritas. Dengan adanya kampanye "Yuk Nabung Saham" bertujuan untuk meningkatkan kesadaran masyarakat untuk berinvestasi di pasar modal dengan membeli saham secara rutin dan berkala.

Selain kampanye "Yuk Nabung Saham", Bursa Efek Indonesia juga mengadakan program sosialisasi dan edukasi mengenai investasi di pasar modal, khususnya kepada kalangan akademisi di kampus, mahasiswa menjadi perhatian khusus dalam program edukasi pasar modal $\mathrm{BEI}$, karena mahasiswa merupakan aset dimasa mendatang yang akan mengisi industri keuangan di pasar modal, (Kusuma: 2013). Guna mendukung program sosialisasi dan edukasi, maka Bursa Efek Indonesia bertekat untuk menambah jumlah galeri investasi sebanyak 45 galeri pada tahun 2016. Dengan dibuka dan ditambahnya jumlah galeri investasi tersebut di harapkan menarik lebih banyak emiten baru dan menambah jumlah investor di pasar modal serta mempermudah kalangan akademisi khususnya mahasiswa untuk melakukan investasi di pasar modal.

Sebagaimana diketahui, galeri investasi Bursa Efek Indonesia (BEI) merupakan sarana untuk memperkenalkan pasar modal sejak dini kepada dunia akademisi. Galeri investasi Bursa Efek Indonesia (BEI) berkonsep 3 in 1 yang merupakan kerjasama antara Bursa Efek Indonesia, perguruan tinggi dan perusahaan sekuritas, dengan adanya galeri investasi diharapkan tidak hanya memperkenalkan pasar modal dari sisi teori saja akan tetapi juga prakteknya.

Universitas Muhammadiyah Gorontalo, merupakan salah satu universitas yang telah mempunyai galeri investasi, di bukanya galeri investasi ini merupakan program kerja sama antara Universitas Muhammadiyah Gorontalo dengan Bursa Efek Indonesia (BEI) dan PT. Phintraco Sekuritas.

Dengan adanya galeri investasi ini, diharapkan menjadi sarana bagi mahasiswa Universitas Muhammadiyah Gorontalo khususnya mahasiswa Fakultas Ekonomi dan IImu Sosial (FEIS) untuk terjun langsung dalam dunia investasi pasar modal dan untuk mempraktekkan teori yang telah didapatkan dalam perkuliahan. Pasar modal memberikan alternatif bagi investor untuk 
berinvestasi baik dalam jangka pendek maupun jangka panjang, yang pada umumnya akan menyebabkan para investor tertarik untuk menginvestasikan dananya.

Dalam perkembangannya Galeri Investasi Bursa Efek Indonesia Universitas Muhammadiyah Gorontalo yang saat ini menjelang 3 tahun berdirinya, progres minat mahasiswa untuk melakukan investasi cukup baik. Sesuai informasi dari pengelola Galeri saat ini sudah mencapai 151 mahasiswa yang membuka rekening saham. Ada beberapa permasalahan yang ditemukan pada galeri investasi, kurang menarik untuk dikunjungi, fasilitasnya kurang menunjang seperti akses internet, kursi serta terbatasnya ruang untuk berkumpulnya mahasiswa dalam mencari informasi.

Berdasarkan penjabaran latar belakang di atas, maka peneliti bermaksud untuk mengadakan penelitian yang berjudul "Keberadaan Galeri Bursa Efek Indonesia Universitas Muhammadiyah Gorontalo Terhadap Minat Mahasiswa Dalam Berinvestasi”.

\section{METODE PENELITIAN}

Penelitian ini mengambil lokasi di Kampus Universitas Muhammadiyah Gorontalo khususnya di Fakultas Ekonomi dan IImu Sosial (FEIS) bulan Agustus Oktober 2019. Untuk mendapatkan data dalam penelitian ini, baik data primer maupun data sekunder, dipergunakan beberapa teknik; 1) Observasi, 2) Kuesioner, 3) Dokumentasi. Analisis data dalam penelitian ini akan dilakukan secara mendalam sebagai upaya mencari dan menata secara sistematis catatan hasil observasi, wawancara dan informasi lainnya untuk meningkatkan pemahaman peneliti tentang kasus yang diteliti.

\section{HASIL DAN PEMBAHASAN}

Galeri Investasi Bursa Efek Indonesia Universitas Muhammadiyah Gorontalo, menaungi sebuah organisasi yang bernama KSPM (Kelompok Studi Pasar Modal). KSPM Universitas Muhammadiyah Gorontalo adalah suatu organisasi yang mewadahi minat serta kemampuan setiap mahasiswa Universitas Muhammadiyah Gorontalo khususnya mahasiswa Fakultas Ekonomi dan IImu Sosial dalam dunia investasi di pasar modal.

KSPM Universitas Muhammadiyah Gorontalo mencanangkan dan melaksanakan beberapa program yang bertujuan mengedukasi serta sebagai wadah inspirasi agar setiap mahasiswa serta masyarakat berminat untuk bergabung dan termotivasi untuk mengelola keuangannya dengan baik melalui inevestasi di Pasar Modal. KSPM Universitas Muhammadiyah Gorontalo adalah gagasan dari Bursa Efek Indonesia perwakilan Manado ibu Foni dan Bapak Harijono Imbran, SE, M.Si sebagai kepala Galeri pertama sehingga KSPM Universitas Muhammadiyah Gorontalo berdiri sejak tanggal 27 Februari 2017. KSPM Universitas Muhammadiyah Gorontalo sekarang beranggotakan kurang lebih 20 orang, yang tidak hanya berlatar belakang dari Fakultas Ekonomi dan IImu Sosial tetapi juga seluruh fakultas yang ada di Universitas Muhammadiyah Gorontalo.

$$
\text { Galeri investasi Universitas }
$$

Muhammadiyah Gorontalo sejak resmi terbentuk, telah menetapkan struktur organisasi dalam rangka menjalankan misi atau eksistensi galeri kedepan. Karena sebagaimana layaknya sebuah organisasi terutama organisasi yang akan membangunan dan mempersiap kompetensi 
sumberdaya manusia khususnya mahasiswa di lingkungan Universitas Muhammadiyah Gorontalo, tentunya Galeri Investasi harus memiliki system dan mekanisme kerja yang terarah dan terukur.

Analisis Keaberadaan Galeri Investasi Universitas Muhammadiyah Gorontalo Terhadap Minat Mahasiswa Dalam Melakukan Investasi

Dalam hal ini berdasarkan penelitian yang telah di lakukan terhadap para responden dalam kurun waktu dua minggu, Penulis dapat memberikan kesimpulan yang telah di kumpulkan berdasarkan responden yang mengetahui kegiatan pasar modal, dan serta mengetahui minat mahasiswa terhadap kegiatan investasi di Pasar modal.

Untuk penilaian atas reponden pengetahuan mahasiswa tentang keberadaan Galeri Ivestasi pasar modal dapat dihitung sebagai berikut:

Untuk mengetahui bobot nilai pertanyaan pengetahuan mahasiswa tentang Galeri Investasi :

Asumsi $100 \%=$ Jumlah Responden

Jumlah Pertanyaan

Untuk mencari presentase mahasiswa yang mengetahui tentang Pasar Modal dengan cara sebagai berikut :

Total Variabel x Bobot Pertanyaan

Maka dapat kita terapkan untuk total reponden yang menjawab dengan jawaban Ya dan jumlah total 40 responden yaitu :

$\mathrm{Ya}=90 \times 0,5=45 \%$

Hasil perhitungan di atas menunjukkan bahwa, dari jumlah responden yang diteliti dengan menggunakan daftar pertanyaan pada kuesioner, ternyata yang menjawab $\mathrm{Ya}$ dari 5 item pertanyaan adalah berjumlah 45 $\%$ atau 18 responden.

Total responden yang menjawab dengan jawaban Tidak dengan jumlah responden sebanyak 40 responden yaitu :

Tidak $=63 \times 0,5 \%=42 \% 31,5$
Hasil perhitungan di atas menunjukkan bahwa, dari jumlah responden yang diteliti dengan menggunakan daftar pertanyaan pada kuesioner, ternyata yang menjawab Tidak dari 5 item pertanyaan adalah berjumlah $42 \%$ atau 17 responden.

Selanjutnya total responden yang menjawab dengan jawaban ragu-ragu dengan jumlah 40 responden yaitu :

Ragu-ragu $=26 \times 0,5 \%=13 \%$

Hasil perhitungan di atas menunjukkan bahwa, dari jumlah responden yang diteliti dengan menggunakan daftar pertanyaan pada kuesioner, ternyata yang menjawab Ragu-ragu dari 5 item pertanyaan adalah berjumlah $13 \%$ atau 5 responden.

Untuk penilaian atas responden tentang minat berivestasi mahasiswa di Pasar Modal dapat di hitung sebagai berikut

Untuk mengetahui bobot nilai pertanyaan responden tentang pengetahuan Pasar Modal sebagai berikut :

Asumsi $100 \% \div$ Jumlah Responden

Jumlah Pertanyaan

Untuk mencari presentase responden yang mengetahui tentang pasar modal dengan cara sebagai berikut :

Total Variabel x Bobot Pertanyaan

Maka dapat di terapakan untuk total responden yang menjawab dengan jawaban Ya dan jumlah total 40 responden sebagai berikut:

$$
\mathrm{Ya}=55 \times 0,83 \%=46 \%
$$

Hasil perhitungan di atas menunjukkan bahwa, dari jumlah responden yang diteliti dengan menggunakan daftar pertanyaan pada kuesioner, ternyata yang menjawab Tidak dari 3 item pertanyaan adalah berjumlah $46 \%$ atau 19 responden.

Total responden yang menjawab dengan jawaban Tidak dengan jumlah total 40 responden sebagai berikut:

$$
\text { Tidak }=40 \times 0,83 \%=33 \%
$$


Hasil perhitungan di atas menunjukkan bahwa, dari jumlah responden yang diteliti dengan menggunakan daftar pertanyaan pada kuesioner, ternyata yang menjawab Tidak dari 3 item pertanyaan adalah berjumlah $33 \%$ atau 13 responden.

Selanjutnya total responden yang menjawab dengan jawaban ragu-ragu dengan jumlah total 40 responden sebagai berikut:

Ragu-ragu $=25 \times 0,83 \%=21 \%$

Hasil perhitungan di atas menunjukkan bahwa, dari jumlah responden yang diteliti dengan menggunakan daftar pertanyaan pada kuesioner, ternyata yang menjawab ragu-ragu dari 3 item pertanyaan adalah berjumlah $21 \%$ atau 8 responden.

\section{Pembahasan}

Pasar modal adalah yang seluruh mekanisme kegiatannya mengenai emiten, jenis efek yang di perdagangkan dan mekanisme perdagangannya telah sesuai dengan prinsip-prinsip pasar modal. Kegiatan pasar modal adalah kegiatan yang halal, karena pada dasarnya kegiatan pasar modal merupakan kegiatan penyertaan modal yang merupakan kegiatan modal dan jual beli efek (saham), sehingga transaksi di pasar modal di perbolehkan. Selama tidak ada larangan yang bertentangan dengan undang yang berlaku terutama tentang undang-undang pasar modal. Dengan adanya galeri investasi Bursa Efek Indonesia di Universitas Muhammadiyah Gorontalo, bisa menjadi pembelajaran praktis dan bermanfaat bagi mahasiswa sehingga dengan banyaknya fasilitas yang sudah ada di harapkan mahasiswa mempunyai minat untuk berivestasi di pasar modal.

Dari penelitian yang telah di lakukan di lingkungan Universitas Muhammadiyah Gorontalo khususnya bagi mahasiswa yang telah memiliki RDN dengan cara menyimpulkan kuisioner, penulis dapat menyimpulkan bahwa mahasiswa Universitas Muhammadiyah Gorontalo mempunyai minat yang cukup besar untuk berinvestasi di pasar modal. Dapat di lihat dari masing-masing instrument sebagai berikut :

\section{Pengetahuan Galeri}

Pengetahuan tentang keberadaan galeri Invetasi Bursa Efek yang telah terbentuk sejak akhir tahun 2017, merupakan suatu hal yang perlu mendapatkan apresiasi dari berbagai stakeholder di lingkungan Civitas Akademika Universitas Muhammadiyah Gorontalo. Karena itu seharusnya keberadaan galeri ini dikenal atau setidaknya menarik bagi mahasiswa, dan seluruh komponen kampus termasuk dosen dan para pegawainya. Namun dari beberapa fakta yang ditemukan dalam penelitian ini yang memfokuskan respondennya para mahasiswa diberbagai fakultas, ternyata menunjukkan gambaran yang belum sesuai dengan ekspetasi seperti yang digambarkan di atas.

Dari beberapa pertanyaan yang telah di ajukan kepada responden, mahasiswa Universitas Muhammadiyah Gorontalo mengetahui tentang pasar modal sebanyak $45,5 \%$, responden mengetahui pasar modal secara umum. Hal ini di sebabkan responden sudah mendapat pengetahuan tentang pasar modal saat masih mulai berdirinya Galeri Investasi Bursa Efek Indonesia di Universitas Muhammadiyah Gorontalo. Jawaban yang menjawab Tidak mendapat presentase sebanyak $41,5 \%$, jwaban ini mengacu tentang keberadaan galeri investasi Bursa Efek Indonesia Universitas Muhammadiyah Gorontalo yang tidak di ketahui sebagian mahasiswa. Jawaban yang menjawa ragu-ragu mendapat presentase sebesar 13\%, jawaban ini mengacu kepada pertanyaan 
tentang produk-produk yang ada di pasar modal. Pengetahuan mahasiswa tentang pasar modal perlu di tingkatkan hal ini bisa di lakukan dengan cara mengedukasi dan mensosialisasikan kepada mahasiswa yang di lakukan oleh pihak Galeri khususnya KSPM (Kelompok Studi Pasar Modal) ke seluruh mahasiswa yang ada di lingkungan Universitas Muhammadiyah Gorontalo. Walaupun sejak berdirinya sudah melalukan sosialisasi, namun intensitasnya dan cakupannya keikutserta mahasiswa dalam sosialisasi masih sangat rendah. Serta peran para dosen merupakan faktor yang dapat mendorong minat mahasiswa untuk berinvestasi di pasar modal. Sehingga dengan pengetahuan tersebut bisa menimbulkan minat yang besar bagi mahasiswa untuk berinvestasi.

\section{Minat Investasi}

Minat adalah suatu keadaan dimana seseorang mempunyai perhatian terhadap sesuatu dan disertai keinginan untuk mengetahui dan mempelajari maupun membuktikan lebih lanjut Bimo Walgito (1981: 38).

Sedangkan menurut Sumadi Suryabrata (2002:68) minat adalah "Suatu rasa lebih suka dan rasa ketertarikan pada suatu hal atau aktivitas tanpa ada yang menyuruh". Minat pada dasarnya adalah penerimaan akan suatu hubungan antara diri sendiri dengan sesuatu hal diluar dirinya. Semakin kuat atau dekat hubungan tersebut semakin besar minatnya. Minat pada seseorang akan suatu obyek atau hal tertentu tidak akan muncul dengan sendirinya secara tiba-tiba dalam diri individu. Minat dapat timbul pada diri seseorang melalui proses. Dengan adanya perhatian dan interaksi dengan lingkungan maka minat tersebut dapat berkembang.

Oleh sebab itu para ahli berpendapat seperti yang dikemukakan oleh Miflen, FJ \&
Miflen FC, (2003:114), bahwa terdapat ada dua faktor yang mempengaruhi minat belajar peserta didik, yaitu; 1) Faktor dari dalam yaitu sifat pembawaan, dan 2) Faktor dari luar, diantaranya adalah keluarga, sekolah dan masyarakat atau lingkungan.

Berdasarkan hasil interpretasi isian kuesioner yang dilakukan selama penelitian pada 40 responden mahasiswa menunjukkan bahwa dari presentase jawaban yang telah didapatkan penulis, penulis dapat menyimpulkan bahwa minat mahasiswa untuk berinvestasi di pasar modal cukup besar, dikarenakan dari jawaban para responden menghasilkan 46 $\%$ untuk jawaban ya, $33 \%$ untuk jawaban tidak dan $21 \%$ untuk jawaban ragu-ragu.

Permasalahan yang ditemui dalam penelitian berdasarkan hasil diskursus dan diskusi ternyata informasi masih rendahnya minat mahasiswa untuk berinvestasi di pasar modal melalui galeri Investasi Universitas Muhammadiyah Gorontalo karena minat yang bersumber dari luas (ekstrinsik) yaitu kurangnya informasi yang diperoleh mahasiswa tentang keberadaan dan aktivitas galeri selama ini. Faktor penyebabnya semata-mata bukan karena pengelolah galeri melainkan karena keterbatasan yang dimiliki baik dari sarana prasarana serta dukungan yang masih belum maksimal dari pihak Universitas dalam hal mendorong animo mahasiswa pada khususnya serta dosen dan para pegawai yang berada di Universitas Muhammadiyah Gorontalo.

Untuk menarik minat mahasiswa untuk berinvestasi di pasar modal diperlukan adanya sosialisasi yang dilakukan secara rutin, agar mahasiswa mengetahui resiko dan keuntungan dari berinvestasi di pasar modal. Selain itu ditubutuhkan penyiapan infrastruktur galeri yang refresentatif, 
misalnya ruangan ber AC, kursi, computer, dan lain sebagainya.

\section{KESIMPULAN}

Dari pembahasan pada bab-bab sebelumnya dapat ditarik kesimpulan sebagai berikut :

a. Keberadaan Galeri Investasi Bursa Efek Universitas Muhammadiyah Gorontalo telah member manfaat baik dari aspek pengetahuan maupun dari aspek manfaat untuk berinvestasi di bursa saham.

b. Pengetahuan mahasiswa tentang keberadaan Galeri Investasi Bursa Efek Universitas Muhammadiyah Gorontalo belum sepenuhnya diketahui dan diminati oleh oleh mahasiswa Universitas Muhammadiyah Gorontalo, hal ini dibuktikan dengan hasil jawaban responden hanya $45 \%$ atau 18 responden dari 40 respon yang menjawab Ya (mengetahui) keberadaan responden. $42 \%$ atau 17 responden yang menjawab tidak tahu, dan $13 \%$ atau 5 responden yang menjawab ragu-ragu.

Minat mahasiswa dalam berinvestasi di Galeri Investasi Bursa Efek Universitas Muhammadiyah Gorontalo sebanyak $46 \%$ atau 19 responden yang menjawab $\mathrm{Ya}$ (berminat), $33 \%$ atau 13 yang menjawab tidak berminat, dan $21 \%$ atau 8 responden yang menjawab ragu-ragu dalam berinvestasi.

\section{SARAN}

Setelah melakukan analisis, maka saran-saran yang dapat penulis berikan adalah sebagai berikut :

1. Galeri Universitas Muhammadiyah Gorontalo perlu miningkatkan promosi dan meningkatkan proses edukasi kepada mahasiswa, karena para mahasiswa masih banyak yang tidak mengetahui tentang pasar modal, produk-produk pasar modal, dan cara berinvestasi di pasar modal. Dengan adanya perkembangan tersebut maka pasar modal dan investasi di pasar modal akan semakin di ketahui oleh seluruh mahasiswa Universitas Muhammadiyah Gorontalo.

2. Galeri Universitas Muhammadiyah Gorontalo perlu meningkatkan kerja sama dengan lembaga Keuangan seperti Otoritas Jasa keuangan dan Bursa Efek Indonesia, hal ini bertujuan untuk meningkatkan pengetahuan mahasiswa tentang pasar modal. Dengan Kerja sama ini juga diharapkan para mahasiswa dapat mengenal Pasar Modal, serta instrument-instrumentnya, sehingga Mahasiswa mempunyai minat untuk berinvestasi di Pasar Modal..

\section{REFERENSI}

Achsien, Iggi H. Investasi Syariah di Pasar Modal: Menggagas Konsepdan Praktikum Manajemen Portfolio. Jakarta: PT GramediaPusaka Utama.

Adi Setiawan Marsis, 2013, Rahasia Terbesar Investasi : agar Kekayaan anda berkembangbiak lebih cepat, Yogyakarta : Second Hope

Ariesto Hadi Sutopo dan Adrianus Arief, 2010. Judul : Terampil Mengolah Data Kualitatif . Penerbit Prenada Media Group : Jakarta

Didit Herlianto, 2013, Manajemen Investasi plus Jurus Mendeteksi Investasi Bodong, Yogyakarta : Gosyen Publishing

Fahmi, Irham Dan Hadi, Yovi Lavianti. 2009. Teori Portofolio danAnalisis Investasi, Teori dan Soal Jawaban, Bandung: Alfabeta.

Fahmi, Irham. 2013. Rahasia Saham dan Strategi Meraih KeuntunganTak 
Terbatas Dalam Bermain Saham Dan Obligasi, Bandung:Alfabeta.

Henry faizal Noor, 2008, Investasi : Pengelolaan Keuangan Bisnis dan Pengembangan Ekonomi Masyarakat,Jakarta: PT.Indeks

Hadi, Nor. 2013. Pasar Modal: Acuan Teoritis dan Praktis Investasi di Instrumen Keuangan Pasar Modal. Yogyakarta: Graha IImu.

Hadi, Syamsul. 2006. Metodologi Penelitian Kuantitatif Untuk Akuntasi Dan Keuangan. Yogyakarta: Ekonisia.

Husnan, Suad. 2009. Dasar-dasar Teori Portofolio \& Analisis Sekuritas.Edisi ke 4. Yogyakarta: UPP STIM YKPN.

Jogiyanto. 2010. Studi Peristiwa: Menguji Reaksi Pasar Modal AkibatSuatu Peristiwa. Yogyakarta: BPFE.

Kuncoro, Mudjarat. 2009. Metode Riset Untuk Bisnis \& Ekonomi,Bagaimana Meneliti \& Menulis Tesis. Edisi ke 3. Jakarta:Erlangga.

Kusuma, Arta Adi.2013. Pengaruh Motivasi dan Lingkungan Kerja Terhadap Kinerja Karyawan Hotel Muria semarang.Skripsi UNES. Semarang

Moleong, Lexy J. 2007, Metodologi Penelitian Kualitatif, Penerbit PT Remaja Rosdakarya Offset, Bandung

Manan,Abdul. 2009. Aspek Hukum Dalam Penyelenggaraan Investasi di Pasar Modal Syariah Indonesia. Jakarta: Kenacan Prenada Media.

Nazir, Moh. 1988. Metode Penelitian. Jakarta: Ghalia Indonesia.

Nagy, R.A., Robert W Obenberger. 1994. Factors Influencing Individual Investor Behavior. Available from: URL: http:/www.Proquest.com

Nor Hadi. 2013. Pasar Modal : Acuan Teoretis Dan Praktis Investasi Di Instrument Keuangan Pasar Modal. Yogyakarta: Graha IImu.

Kotler, Philip dan Gary Amstrong. 2001. Prinsip-Prinsip Pemasaran.Jakarta: Erlangga.
R.J Shook, Pengertian Pasar Modal.

Sakaran, Uma. 2006. Metodologi Penelitian Untuk Bisnis 2. Jakarta:Salemba empat.

Salim, dan Sutrisno, Budi. 2008. Hukum Investasi di Indonesia. Jakarta:PT Raja Grafindo Persada.

Septyanto, Dihin. 2013. "Faktor-Faktor Yang Mempengaruhi Investor Individu Dalam Pengambilan Keputusan Investasi Sekuritas Di Bursa Efek Indonesia (BEI)". Jurnal Ekonomi. Universitas Esa Unggul Jakarta. Volume 4, Nomor 2.

Siegel Joel G. dan Jae K. Shim,1999, Kamus Istilah Akuntansi. Elex Media Komputindo. Jakarta.

Sugiyono. 2013. Statistik Untuk Penelitian. Bandung: Alfabeta.

Sunariyah. 2003. Pengantar Pengetahuan Pasar Modal. Yogyakarta:UPP AMP YKPN.

Salim dan Sutrisno, Budi. 2008. Hukum Investasi di Indonesia. Jakarta:PT Rajagrafindo Persada.

Tandelin, Eduardus. 2001. Analisis Investasi dan Manajemen Portofolio.Edisi pertama. Yogyakarta: BPFE.

Witherington, H.C alih bahasa oleh M. Buchori. 1978. Psychologypendidikan. Jakarta: Aksara Baru. 